This item was submitted to Loughborough's Research Repository by the author.

Items in Figshare are protected by copyright, with all rights reserved, unless otherwise indicated.

\title{
A survey of prosthetic preferences in the UK and Greece
}

\section{PLEASE CITE THE PUBLISHED VERSION}

http://www.drs2018limerick.org/participation/proceedings

\section{PUBLISHER}

Design Research Society

\section{VERSION}

VoR (Version of Record)

\section{PUBLISHER STATEMENT}

This work is made available according to the conditions of the Creative Commons Attribution-NonCommercialShareAlike 4.0 International (CC BY-NC-SA 4.0) licence. Full details of this licence are available at: http://creativecommons.org/licenses/by-nc-sa/4.0/

\section{LICENCE}

CC BY-NC-SA 4.0

\section{REPOSITORY RECORD}

Vlachaki, Anna, Abby Paterson, C. Samantha Porter, and Richard J. Bibb. 2019. "A Survey of Prosthetic Preferences in the UK and Greece". figshare. https://hdl.handle.net/2134/35069. 


\title{
A survey of prosthetic preferences in the UK and Greece
}

\author{
VLACHAKI Anna ${ }^{a^{*}}$; PATERSON Abby M.J. ${ }^{a}$ PORTER C. Samantha ${ }^{a}$ and BIBB Richard J. ${ }^{a}$ \\ a Loughborough University, United Kingdom \\ * Corresponding author e-mail: a.vlachaki@lboro.ac.uk \\ doi: $10.21606 /$ dma.2017.232
}

\begin{abstract}
People with limb loss are considered as disabled and they are stigmatised. However, the use of prostheses that express their identity has potential to change society's opinion and eliminate stigmatisation. Using an online questionnaire, the aim of the study was to understand users' preferences towards prostheses and whether culture affects them with the aim of designing more suitable prostheses for them. In order to investigate people's preferences, with respect to cultural diversity, the study was conducted in the UK and Greece. There were 136 valid answers. The sample methods of the research are non-probability. Through the demographic and disability related variables that were tested, age and cause of limb loss appear to be independent of culture. The results present similarities between the two countries regarding the hierarchy of the preferences. However, the reasons for participants' preferences towards prosthetic limbs significantly differ; in the UK people are concerned about identity, whilst in Greece the concern is for social reasons. Functional concerns constitute the most important issues to both countries.
\end{abstract}

Keywords; prostheses; preferences; culture; stigma

\section{Introduction}

Sethna and Blythe (2016) describe culture as a "set of shared beliefs, attitudes and behaviours associated with a large and distinct group of people" (p.406) and since culture is something that people learn during their life, it affects their behaviour and habits to a great extent. In order to separate and distinguish the world, people use cultural categories; the most significant are those created in human community, such as gender, age, occupation etc. (McCracken, 1986). The products people use can help them discriminate others into the various cultural categories due to the symbolic meanings they have (McCracken, 1986; McDonagh, Bruseberg \& Haslam, 2002).

One way to understand culture is by dividing it into High/ Low Context (Sethna \& Blythe, 2016). People who live in High Context (HC) cultures have strong values, attitudes and perceptions, their behaviour is stable and predictable, they can communicate with non-verbal cues and they are collectivist (Würtz, 2005; Sethna \& Blythe, 2016). On the other hand, the values, attitudes and 
perceptions of people in Low Context (LC) cultures can change easily, they communicate with clear messages and they are individualist (Würtz, 2005; Sethna \& Blythe, 2016). Hofstede (1984) was the first who referred to the cultural dimensions of societies; those of power distance, uncertainty avoidance, individualism/collectivism, masculinity/femininity and long-term orientation (Tsikriktsis, 2002; Yaveroglu \& Donthu, 2002). The research that Yaveroglu and Donthu (2002) conducted shows that people who live in countries with high power distance tend towards imitation. People in countries presenting low levels of uncertainty avoidance will be more innovative and easily accept different opinions from their own whilst people in countries with high levels of uncertainty avoidance present higher levels of imitation and will not accept diversity (Yaveroglu \& Donthu, 2002). In individualistic societies people act independently and autonomously, are motivated by their personal goals and take individual decisions (Goncalo \& Staw, 2006; Yaveroglu \& Donthu, 2002). People in collectivistic societies create strong bonds with groups, they are influenced by them and try to maintain the harmony in the group (Goncalo \& Staw, 2006; Yaveroglu \& Donthu, 2002). Yaveroglu and Donthu (2002) and Würtz (2005) compare Hofstede's individualistic/ collectivist dimensions of culture with Hall's LC/ HC cultures and suggest that the two theories present similarities concerning social interactions.

Table 1 The characteristics of Greece and the UK according to Hall's division of cultures and Hofstede's cultural dimensions (Papadopoulos, 2009).

\begin{tabular}{lcc}
\hline Countries & Greece & UK \\
\hline Context & High & Low \\
\hline Orientation & Collectivism & Individualism \\
\hline Power distance & High & Low \\
\hline Uncertainty avoidance & High & Low \\
\hline
\end{tabular}

Deal (2003) supports that the attitudes people have towards others with impairments are affected by the culture and the type of impairment. Saetermoe, Scattone and Kim (2001) refers to the study that Jaques, Linkowski and Sieka (1970) conducted in three countries and shows that Americans, in comparison to Greeks, present higher tolerance towards people with disabilities. These results are in accordance with the research of Westbrook, Legge and Pennay (1993), which also highlights the importance of culture on the formation of people's attitudes and shows that Germans (individualistic) appear to have the most positive attitudes towards disabled, while the Greek (collectivism) have the most negative, due to the social stigma that easily spreads to the members of the group. The same findings are also derived from the study of Zaromatidis, Papadaki and Gilde (1999), which shows that the culture in which people grow up affects attitudes as Greeks appeared to be more negative towards individuals with impairments than Greek-Americans and suggest that this is a result of collectivism/ individualism. Papadopoulos (2009) points out that Greek-Cypriot who confront mental problems are stigmatised more than British. Additionally, in a comparison between the two cultures, the British appeared to have a less stigmatised view than Greeks although both of them had a negative opinion (Papadopoulos, 2009). The study that Grames and Leverentz (2010) conducted shows that culture and type of disability play an important role in the formation of people's attitudes, since the Chinese (collectivism) present more positive attitudes than Americans (individualism) towards people with physical problems and less towards people with psychiatric disability problems. Although these studies describe Greece as a collectivism culture, the investigations of Georgas (1989) and Pouliasi and Verkuyten (2011) point out that the urban societies of Greece are in a transitional phase from societies of collectivism to individualism.

People with limb loss are often considered as disabled by the able-bodied since their body does not comply with the standards of normalcy of the human body that modern societies impose. As a 
result, they are stigmatised. Stigma is based on the relationship that exists between the person who is considered to have a difference and the other people who evaluate and perceive this difference negatively (Green, Karshmer, Marsh \& Straight, 2005; Riddell \& Watson, 2003; Susman, 1994). From this interaction, there are two types of stigma; public and self-stigma. According to Werner and Shulman (2015), public stigma derives from the opinion of society towards stigmatised people, while self-stigma is a consequence of the opinion that the individual forms, based on society's attitude. Green et al. (2005) and Werner and Shulman (2015) highlight that stigma can also spread to people who are close to those who experience stigma, such as the members of the family and it is referred as stigma by association. Goffman, cited in Susman (1994), reports that normal people try to avoid socialising with stigmatised groups because they feel that stigma will spread to them. This behaviour results in the categorisation of people into desirable and undesirable groups and causes negative feelings towards the undesirable groups, such as emotional distress and depression which lead to social discomfort (Rybarczyk et al., 1992; Werner \& Shulman, 2015). These feelings are experienced not only by people with disabilities, but also by the members of their family (Green et al., 2005; Werner \& Shulman, 2015) and they can affect their social life and identity, as well as the validity of their actions or beliefs (Murray, 2005; Zola, 1993). In order to change the perception that exists towards people with limb loss and eliminate stigma, it is important to transform the negative evaluation into positive. This may be achieved through the combination of medical and fashion design.

\subsection{Changing society by designing fashionable prostheses}

Simon (2014) and Kongprasert (2012) highlight the power of fashion to connect with culture, politics and personal identity. Throughout the years various fashion trends have been used by people in different subcultures in order to express beliefs and values or question the cultural and social norms. Pullin (2009) and Vainshtein (2011) highlight the contribution of fashion to people with disabilities, by mentioning as an example the evolution of glasses, and maintain that fashion can help them fight against the societal norms of oppression and marginalisation by using products which highlight their impairment, in order to make clear the statement that they are not a stigmatised group. As Pullin (2009) says, "a more confident and accomplished design could support more positive images of disability" (p.15).

The development of Additive Manufacturing (AM), during the last decade, and its incorporation in the design process of prostheses has led to new directions. Designers such as Scott Summit (2011), The ALLELES Design Studio Ltd (2017) and Aviya Serfaty (Kim, 2010) declare that by transforming prosthetic parts into accessories users can highlight their identity. Aimee Mullins (2009) maintains that prostheses can be used not only as products which replace mobility, but also as symbols with which users can build their own identities and stop being considered as disabled. In their review about the design of prostheses, Hall and Orzada also point out the significance of fashion in the creation of social meanings which are contrary to those based on the normalcy of the human body by saying that:

If one concedes that limb loss is a violation of the normative body, then bringing attention to it would be making a social statement, one that rejects societal pressure to conform to the normative embodied ideal. From this perspective, style, in the form of expressive prostheses, could be used by persons with limb loss to make this positive social statement. Prostheses that solicit attention would emphasize individual uniqueness and highlight yet another aspect of diversity within the contemporary society. (Hall \& Orzada, 2013, pp. 26-27).

Prosthetic limbs that can increase users' confidence can eliminate self-stigma. If people with limb loss feel confident about themselves and their body image, they can affect the attitudes that people around them (e.g. family, friends) have regarding their condition and as a result reduce the stigma by association which may lead to a restriction of public stigma. Nevertheless, although there are a 
variety of available prostheses, a recent study conducted by Cairns, Murray, Corney and McFadyen (2014) proves that the majority of people with amputation are not satisfied with the prosthetic limbs they use. This may be a result of the lack of research that exists concerning the research area of users' preferences towards prosthetic limbs and the factors that can affect these preferences.

\section{Research Methods}

\subsection{Terminology of research}

The terms prosthesis or prosthetics are used in order to describe the artificial devices which replace lost parts of the body (e.g. teeth, fingers, arms, legs etc.) and they are used for functional and/or aesthetic purposes (Prosthetic devices, n.d.; Sansoni, Wodehouse, McFadyen \& Buis, 2015). In this study, these terms describe only the artificial devices that are used by people with upper and/or lower limb loss, such as arms and/or legs.

In literature, different terms are used in order to describe the types of prostheses that exist. The prosthetic limbs that imitate the human limbs visually (Figure 1a) are usually referred as cosmesis or cosmetic devices (Hall \& Orzada, 2013; Pullin, 2009; Sansoni, Wodehouse \& Buis 2014). In this paper, these prostheses will be mentioned as Realistic Prostheses (RP). The prosthetic limbs that focus on functional aspects and have a robotic design (Figure $1 \mathrm{~b}$ ) will be referred as Functional Prostheses (FP). Finally, for the prosthetic limbs that focus on aesthetic aspects with an aim to highlight the personality and the identity of the wearer (Figure 1C), will be described using a term that Hall and Orzada (2013) introduced; Expressive Prostheses (EP).
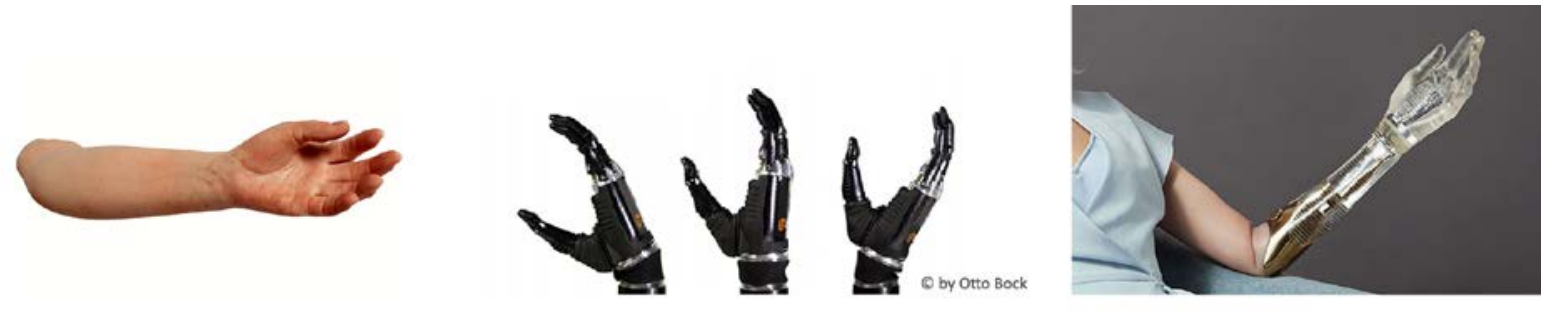

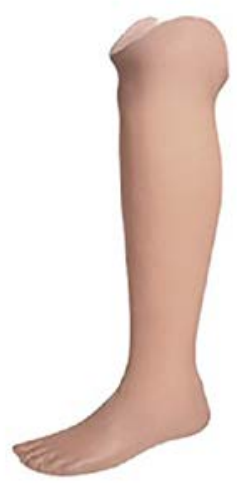

a- RP

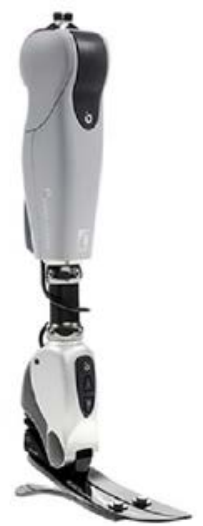

b-FP

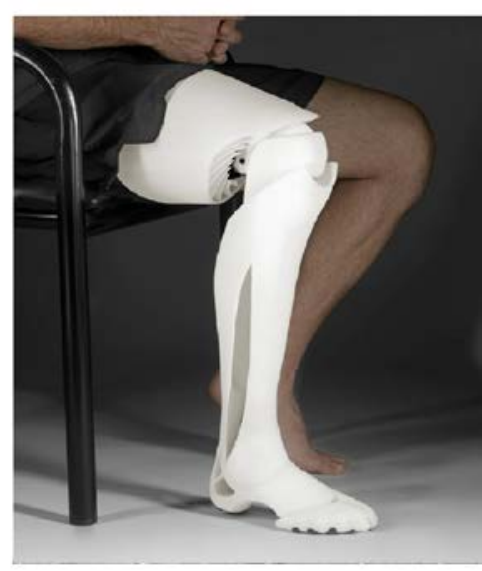

C - EP

Figure 1 a. Above: Realistic prosthetic limb for upper limb loss made of silicon. Designed in 2013 by Sophie de Oliveira Barata. source: The alternative limb project (2018). Below: The Dream Skin prosthetic limb for lower limb loss by Fillauer Company. source: Fillauer (2018); b. Above: bebionic Hand designed by RSL Steeper. source: Otto Bock HealthCare GmbH (2017). Below: The RHEO Knee. source: Össur (2018); c. Above: The Synchronised prosthetic arm designed in 2017 by Sophie de Oliveira Barata and Dani Clode. Photographed by Omkaar Kotedia and used by Kelly Knox. source: adjusted by The alternative limb project (i) (2018). Below: Custom made 3D printed prosthetic limb from Bespoke Innovations designed in 2008 by Scott Summit. source: adjusted by SummitID (2017).

The categorisation of the artificial limbs into realistic, functional and expressive was used in the survey, which is analysed in the next sections of the paper, and were used to the better understand of the types of prostheses that participants use and prefer. 


\subsection{Aim and Objectives}

The aim of the study was to investigate users' preferences towards the three types of prostheses (RP, FP, EP) in order to understand whether people's preferences are affected by the culture in which they live.

The objectives were:

1. To critically analyse prior knowledge about issues surrounding cultural impacts of prostheses.

2. To gather insights with respect to the two cultures being studied as well as the demographic and disability related variables.

3. To explore the reasons that the disability variables and culture have led participants to their choices.

4. To establish key criteria which drive users preference based on the cultural context of the two countries and compare them with previous investigations in order to evaluate which variables influence their choices.

\subsection{Questionnaire and Variables}

The study was based on quantitative methods. One of the instruments that is used in quantitative methods, in order to gather large numbers of data in a particular time period and determine relationships between the variables, are surveys which can be conducted using questionnaires (Cohen, Manion \& Morrison, 2011).

The questionnaire consisted of sixteen closed questions and one open question in which users who own prostheses that belong to more than one of the three types (RP, FP, EP) described their prostheses. Thirteen questions were multiple choice, two were dichotomous and one was a grid. Six of the questions were based on demographic data (age, sex, nationality, residence, educational level and annual income) and were four about disability related characteristics (area/ level and cause of limb loss, time since operation and years of wearing prosthetic $\operatorname{limb}(\mathrm{s})$ ). Two of the questions were pictures that depict prosthetic limbs which were separated into the three types of prostheses (RP, $F P, E P)$. In these questions participants had to choose the category in which the prosthetic limb they already have fits. If they were not satisfied with the limb they already have, they needed to choose the prosthesis they would most like to have and give reasons of their choice. In the last question, participants had to state what they think about their appearance with respect to the prosthetic limb they already use. All the variables tested were derived from previous investigations which show what may constitute factors that can affect people with limb loss.

\subsection{Participants}

Amputees and people with congenital limb loss constitute a sample that it is difficult to approach. Many people with limb loss are isolated from others as they have not accepted the limb loss and deny speaking about it. Nevertheless, there are few ways through which researchers can contact them. One way is through support or sport groups, charities and organisations. The second way is through clinics (private or NHS) and the third way is individually or through groups on the social media. However, conducting research with patients of the National Health Service (NHS) of the UK requires additional ethics approval; that from the Research Ethics Committee (REC). As Robson and McCartan (2016) point out, getting an approval from NHS is a very difficult and time consuming process and there are many factors that affect the process. As a result of the fact that NHS patients could not be reached, as the author did not have a REC approval, volunteer and snowball methods were adopted for the conduct of the study. Table 2 depicts the number of people the author conducted. However, these methods usually are not representative of the population. Another reason that contributes to the sample not being representative was the exclusion criteria which were: 
- Being under 18 years old.

- Do not own prosthetic limb(s).

- Have not been born and grow up in Greece or in the UK.

Table 2 The number of people the author contacted in order to ask them to participate in the research and/or inform other people. Snowball (i) and volunteer (ii) methods.

\begin{tabular}{lccc}
\hline Contacts & UK & Greece & Total \\
\hline Private Companies (ii) & 5 & 11 & 16 \\
\hline Support groups and Charities (i, ii) & 35 & 13 & 48 \\
\hline Private Clinics (ii) & 5 & 2 & 7 \\
\hline Organisations (i, ii) & 3 & 3 & 6 \\
\hline Sport groups (i, ii) & 11 & 26 & 37 \\
\hline Individuals (i) & 7 & 8 & 15 \\
\hline Social Media (Facebook and Blogs) (ii) & 6 & 1 & 7 \\
\hline Responses & & & 30 \\
\hline Not answered & 17 & 23 & 49 \\
\hline Negative & 26 & 30 & 57 \\
\hline Willing to help & 27 & $20 / 30$ & $42 / 57$ \\
\hline Helped & $22 / 27$ & & \\
\hline
\end{tabular}

\subsection{Completion of questionnaire}

Most of the participants completed the questionnaire online. However, in eight cases the questionnaires were given to participants as hard copy as participants were older in age with limited or no access to the Internet. In the introduction of the questionnaire, two links were provided to the Participant Information and the Informed Consent Form. Participants who accepted the conditions described in the Informed Consent Form continued to the questionnaire. Participants who did not answer more than two questions were excluded from the analysis.

\subsection{Ethics}

The study was approved by the Ethics Sub-Committee for Human Participants of Loughborough University. Full ethical approval required the submission of the Participant Information, the Informed Consent Form, the Risk Assessment Form, the Ethical Clearance Checklist and the Research Proposal for Studies Involving Human Participants.

\section{Results}

As the sampling methods of the survey were non-probability, only descriptive statistics were used with visual means in order to describe the findings of the survey. Microsoft Excel 2010 was used for the coding of the findings, as well as their analysis and the production of the visuals.

The questionnaires were completed by 157 people (78 participants from the UK and 76 participants from Greece). Twenty-one responses were excluded from the analysis due to the exclusion criteria described in the Participants section of the paper. The total number of valid answers was 136 (87\%) with 67 participants from the UK and 69 from Greece. In both countries, the majority of participants were male. In the UK most of the people who completed the questionnaire were above 45 years old while in Greece, most of the participants were below 45 years old (see Table 3).

Concerning the prosthetic limbs participants own, in the UK the majority of participants answered that they own RP (49\%) while in Greece most of the participants have FP (54\%). In both countries, EP has the lowest percentages ( $9 \%$ in the UK and $1 \%$ in Greece). However, half of the total number of participants said that they would like to use a different prosthetic limb as they are not satisfied with the one they own. Similarities between the two countries are presented regarding the ranking order 
of the prosthetic limbs participants prefer. Based on the findings, FP is first in the participants' preferences; EP comes second and last is the RP.

Table 3 The percentages of participants from Greece (GR) and the UK regarding their age and sex. The parentheses present the actual number of participants.

\begin{tabular}{|c|c|c|c|c|c|c|c|c|c|c|c|c|}
\hline \multirow{3}{*}{$\begin{array}{l}\text { Age } \\
18 \text { to } 29\end{array}$} & \multicolumn{6}{|c|}{$\overline{G R}$} & \multicolumn{6}{|c|}{ UK } \\
\hline & \multicolumn{2}{|c|}{ Males } & \multicolumn{2}{|c|}{ Females } & \multicolumn{2}{|c|}{ GR Total } & \multicolumn{2}{|c|}{ Males } & \multicolumn{2}{|c|}{ Females } & \multicolumn{2}{|c|}{ UK Total } \\
\hline & $20 \%$ & (14) & $4 \%$ & (3) & $25 \%$ & (17) & $0 \%$ & (0) & $7 \%$ & (5) & $7 \%$ & (5) \\
\hline 30 to 44 & $20 \%$ & (14) & $6 \%$ & (4) & $26 \%$ & (18) & $4 \%$ & (3) & $12 \%$ & (8) & $16 \%$ & (11) \\
\hline 45 to 59 & $28 \%$ & (19) & $6 \%$ & (4) & $33 \%$ & (23) & $25 \%$ & (17) & $19 \%$ & (13) & $45 \%$ & (30) \\
\hline $60+$ & $9 \%$ & (6) & $7 \%$ & (5) & $16 \%$ & (11) & $24 \%$ & (16) & $7 \%$ & (5) & $31 \%$ & (21) \\
\hline Grand Total & $77 \%$ & (53) & $23 \%$ & (16) & $100 \%$ & (69) & $54 \%$ & (36) & $46 \%$ & (31) & $100 \%$ & (67) \\
\hline
\end{tabular}

The analysis of the reasons that participants chose the prosthetic limbs they prefer with respect to their nationality (see Figure 2) presents differences between the two countries. Although functional reasons ('Both Functionality and Aesthetics', 'Great Mobility', 'High Functionality') are the priority for people in both countries, Greek participants have also chosen social reasons, such as 'Not Attract Attention' and 'Normal Body Appearance', while participants from the UK emphasise identity reasons, such as 'Highlight Personality', 'Suits my Style'. 'Participation in Everyday Activities' has been ranked high to both countries.

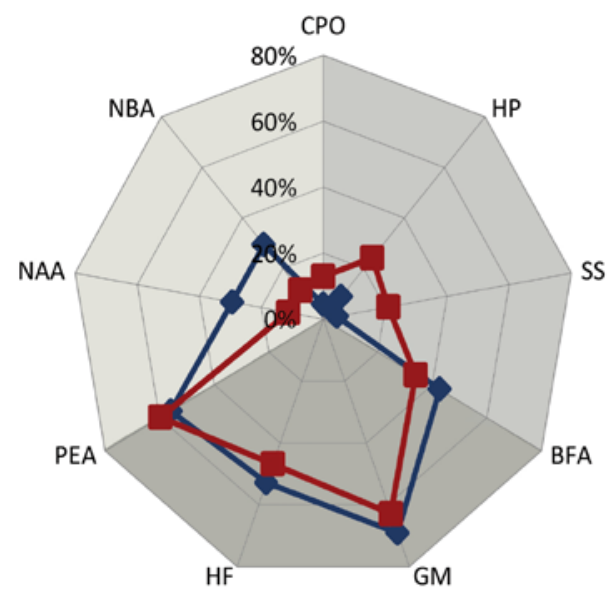

\begin{tabular}{l|l} 
CPO: Change People's Opinion & Identity \\
HP: Highlight Personality & Reasons \\
SS: Suits my Style &
\end{tabular}

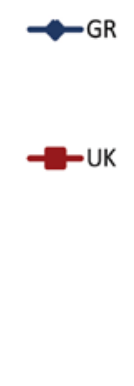

\begin{tabular}{l|c} 
BFA: Both Functionality and Aesthetics & Functional \\
GM: Great Mobility & Reasons \\
HF: High Functionality &
\end{tabular}

\begin{tabular}{l|c} 
PEA: Participation in Everyday Activities & Social \\
NAA: Not Attract Attention & Reasons \\
NBA: Normal Body Appearance &
\end{tabular}

Figure 2 The reasons for which Greek (GR) people and people from the UK chose the prosthetic limb they prefer.

\subsection{Demographic characteristics}

The findings of the study regarding sex show that FP has been chosen as the most preferable prostheses among both sexes in both countries. In Greece, the order of RP and EP is not clear, since they present similar proportions. However, in the UK, male preferences towards RP and EP are the reverse of that of females, as EP is the least preferable prostheses for males and RP for females (see Table 4). Regarding the prosthetic limbs participants want and age FP has the highest percentages among all age groups except the one with the UK participants who are over sixty years old and prefer RP. Additionally, it can be noticed that in both countries, EP comes second for participants who are 18 to 59 years old, while for participants over 60 years old, EP is the least preferred type of prostheses (see Table 4). 
Table 4 Participants' preferences towards the three types of prostheses regarding country and demographic variables. The parentheses present the actual number of participants (N.P.) of each country to each subgroup.

\begin{tabular}{|c|c|c|c|c|c|c|c|c|}
\hline \multirow[b]{2}{*}{ Demographic variables } & \multicolumn{4}{|c|}{ GR } & \multicolumn{4}{|c|}{ UK } \\
\hline & $\mathrm{RP}$ & FP & EP & N.P. & RP & FP & EP & N.P. \\
\hline \multicolumn{9}{|l|}{ Sex } \\
\hline Males & $10 \%$ & $79 \%$ & $11 \%$ & (53) & $26 \%$ & $60 \%$ & $14 \%$ & (35) \\
\hline Females & $19 \%$ & $62 \%$ & $19 \%$ & $(16)$ & $16 \%$ & $48 \%$ & $36 \%$ & (31) \\
\hline \multicolumn{9}{|l|}{ Age } \\
\hline 18 to 29 & $12 \%$ & $70 \%$ & $18 \%$ & $(17)$ & $20 \%$ & $40 \%$ & $40 \%$ & (5) \\
\hline 30 to 44 & $0 \%$ & $83 \%$ & $17 \%$ & $(18)$ & $9 \%$ & $64 \%$ & $27 \%$ & $(11)$ \\
\hline 45 to 59 & $13 \%$ & $74 \%$ & $13 \%$ & (23) & $7 \%$ & $62 \%$ & $31 \%$ & (29) \\
\hline $60+$ & $27 \%$ & $73 \%$ & $0 \%$ & $(11)$ & $48 \%$ & $43 \%$ & $9 \%$ & $(21)$ \\
\hline \multicolumn{9}{|l|}{ Educational level } \\
\hline Secondary School & $10 \%$ & $77 \%$ & $13 \%$ & (31) & $35 \%$ & $60 \%$ & $5 \%$ & $(20)$ \\
\hline Further Education & $0 \%$ & $85 \%$ & $15 \%$ & (13) & $11 \%$ & $54 \%$ & $35 \%$ & $(26)$ \\
\hline High Education & $20 \%$ & $68 \%$ & $12 \%$ & $(25)$ & $20 \%$ & $50 \%$ & $30 \%$ & $(20)$ \\
\hline \multicolumn{9}{|l|}{ Annual income } \\
\hline No income & $14 \%$ & $72 \%$ & $14 \%$ & (7) & $0 \%$ & $100 \%$ & $0 \%$ & (4) \\
\hline Very Low & $0 \%$ & $88 \%$ & $12 \%$ & (17) & $22 \%$ & $53 \%$ & $25 \%$ & (36) \\
\hline Low & $13 \%$ & $71 \%$ & $16 \%$ & (31) & $25 \%$ & $50 \%$ & $25 \%$ & $(16)$ \\
\hline High & $20 \%$ & $70 \%$ & $10 \%$ & (10) & $17 \%$ & $50 \%$ & $33 \%$ & (6) \\
\hline Very High & $25 \%$ & $75 \%$ & $0 \%$ & (4) & $25 \%$ & $50 \%$ & $25 \%$ & (4) \\
\hline \multicolumn{9}{|l|}{ Area of residence } \\
\hline City & $9 \%$ & $76 \%$ & $15 \%$ & $(55)$ & $30 \%$ & $35 \%$ & $35 \%$ & $(26)$ \\
\hline Town & $33 \%$ & $67 \%$ & $0 \%$ & (6) & $17 \%$ & $69 \%$ & $14 \%$ & (29) \\
\hline Village & $17 \%$ & $83 \%$ & $0 \%$ & (6) & $11 \%$ & $78 \%$ & $11 \%$ & (9) \\
\hline Hamlet/Countryside & $0 \%$ & $50 \%$ & $50 \%$ & $(2)$ & $0 \%$ & $0 \%$ & $100 \%$ & (2) \\
\hline
\end{tabular}

The findings concerning educational level show that in both countries, FP has the highest percentage of all categories. RP is not a significant percentage among participants with further education, while the percentages of RP and EP are reversed between the two countries; Greek participants with high levels of education have the lowest preference towards EP and UK participants towards RP. FP is the most preferable to all categories of annual income. However, Greek participants with a high level of annual income prefer more RP than EP, while the participants from the UK who belong to the same category do prefer EP. Greek participants with very low level of annual income seem to like more the $E P$, which is contrary to the participants with a very high level of annual income who have chosen $\mathrm{RP}$. In case of the participants from the UK, the results towards the preferences of RP and EP are not so clear. Only in case of participants who have high income, where EP appears to be more preferable than RP. The results regarding the area of residence, in case of the UK, are not clear; on the other 
hand, Greek participants' preferences seem to be affected by the area of their residence. Although the results are not representative, none of the Greek participants who have chosen 'Town' or 'Village' as the area of their residence chose EP.

The analysis of the reasons that female and male participants chose the prosthetic limbs they would like to use shows that the reasons NNA, NBA and HP are higher in female participants of both countries than in male participants, whilst CPO is also higher in the females from the UK. Concerning education and annual income, the longest difference in hierarchy between the two countries is observed in the categories 'High Education' and 'High' income. Analysis of the reasons and literature do not give further explanations. As the preferences of Greek participants seem to be affected by the area they live, a further analysis on the reasons due to which Greek participants who live in cities $(C)$, towns $(T)$, villages $(V)$ and countryside $(C / S)$ chose the prosthetic limb they prefer was conducted. The analysis of the answers shows that NAA and NBA are higher in case of Greek people who live in villages and towns and lower in cases of city and countryside (see Figure 3).

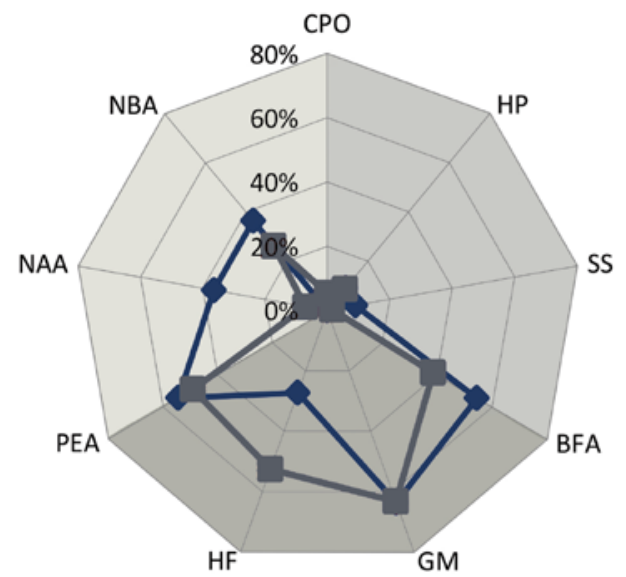

CPO: Change People's Opinion
HP: Highlight Personality
SS: Suits my Style

Figure 3 The reasons for which Greek (GR) chose the prosthetic limb they prefer regarding the area of their residence.

\subsection{Disability related characteristics}

One of the disability related variables is the time that has passed since the amputation, which is similar to the number of the years that the participants have worn prosthetic limbs; with $98 \%$ of them answering that they have owned prostheses for the same time period as that that has passed since amputation. Participants who wear prostheses for a short time period ( 0 to 4 years) show a preference to FP, especially in Greece (see Table 5). For Greek participants who wear prostheses for 5 to 14 years, EP is a more desirable option than RP, whilst on UK participants more preferred are RP and EP. Finally, for those who wear prostheses for more than 15 years, FP has the highest proportion of responses in both countries whilst the percentages of RP and EP are close. Concerning the cause of limb loss, the two countries demonstrate the same hierarchy of the three types of prostheses. More specifically, FP have been ranked as the most preferable prostheses for all categories; in participants who have the amputation due to trauma/accident reasons, RP is the least preferred, while in participants with congenital limb loss, the least preferred type is EP. Finally, the area of limb loss, as well as the level of limb loss do not appear to influence users' preferences. 
Table 5 Participants' preferences towards the three types of prostheses regarding country and disability related variables. The parentheses present the actual number of participants (N.P.) of each country to each subgroup.

\begin{tabular}{|c|c|c|c|c|c|c|c|c|}
\hline \multirow[b]{2}{*}{ Disability related variables } & \multicolumn{4}{|c|}{ GR } & \multicolumn{4}{|c|}{ UK } \\
\hline & $\mathrm{RP}$ & FP & EP & N.P. & $\mathrm{RP}$ & FP & EP & N.P \\
\hline \multicolumn{9}{|l|}{ Years since amputation } \\
\hline 0 to 4 & $0 \%$ & $100 \%$ & $0 \%$ & (13) & $7 \%$ & $75 \%$ & $18 \%$ & (28) \\
\hline 5 to 14 & $0 \%$ & $84 \%$ & $16 \%$ & (19) & $35 \%$ & $30 \%$ & $35 \%$ & (17) \\
\hline $15+$ & $16 \%$ & $68 \%$ & $16 \%$ & $(25)$ & $31 \%$ & $46 \%$ & $23 \%$ & (13) \\
\hline \multicolumn{9}{|l|}{ Years wear prostheses } \\
\hline 0 to 4 & $0 \%$ & $100 \%$ & $0 \%$ & (14) & $7 \%$ & $73 \%$ & $20 \%$ & (30) \\
\hline 5 to 14 & $5 \%$ & $76 \%$ & $19 \%$ & (21) & $42 \%$ & $26 \%$ & $32 \%$ & (19) \\
\hline $15+$ & $18 \%$ & $67 \%$ & $15 \%$ & (34) & $24 \%$ & $52 \%$ & $24 \%$ & (17) \\
\hline \multicolumn{9}{|l|}{ Cause } \\
\hline Disease & $17 \%$ & $66 \%$ & $17 \%$ & $(12)$ & $32 \%$ & $44 \%$ & $24 \%$ & (34) \\
\hline Trauma/Accident & $6 \%$ & $81 \%$ & $13 \%$ & $(48)$ & $4 \%$ & $69 \%$ & $27 \%$ & (26) \\
\hline Congenital & $33 \%$ & $56 \%$ & $11 \%$ & (9) & $33 \%$ & $50 \%$ & $17 \%$ & (6) \\
\hline \multicolumn{9}{|l|}{ Area of limb loss } \\
\hline Upper & $23 \%$ & $54 \%$ & $23 \%$ & $(12)$ & $0 \%$ & $89 \%$ & $11 \%$ & (10) \\
\hline Lower & $9 \%$ & $80 \%$ & $11 \%$ & (56) & $25 \%$ & $49 \%$ & $26 \%$ & (57) \\
\hline \multicolumn{9}{|l|}{ Level of limb loss } \\
\hline Single & $12 \%$ & $76 \%$ & $12 \%$ & (59) & $19 \%$ & $58 \%$ & $23 \%$ & (55) \\
\hline Double & $14 \%$ & $71 \%$ & $14 \%$ & (7) & $36 \%$ & $36 \%$ & $28 \%$ & (12) \\
\hline
\end{tabular}

The analysis of the reasons that participants who had their amputation 0 to 4 years ago chose the prostheses they prefer shows that functional reasons are the most popular in both countries (see Figure 4). However, participants from the UK are also worried about the consequences of limb loss on their appearance and identity (CPO, HP, SS), reasons which still remain high for participants who had their amputation five years ago or more. Contrary to the UK, Greek participants appeared to worry more after the amputation for social reasons and the consequences that the limb loss will have on their social life (NBA, NAA), probably due to stigma. The analysis of the reasons participants chose the prosthetic limb they would like to use with respect to the cause of the limb loss show that functional reasons are the most important among all categories. However, in the case of participants who had limb loss due to trauma, Greek participants present a high proportion of social reasons (NAA, NBA), whilst the UK participants focus on identity (HP, SS, CPO). In the case that the amputation was caused by disease, social reasons and especially those of NBA and CPO, are high in both countries. In case of congenital limb loss, participants from both countries have chosen social (NBA, NAA) and identity (HP) reasons, while none of the participants chose CPO and SS as reasons of their choice. 

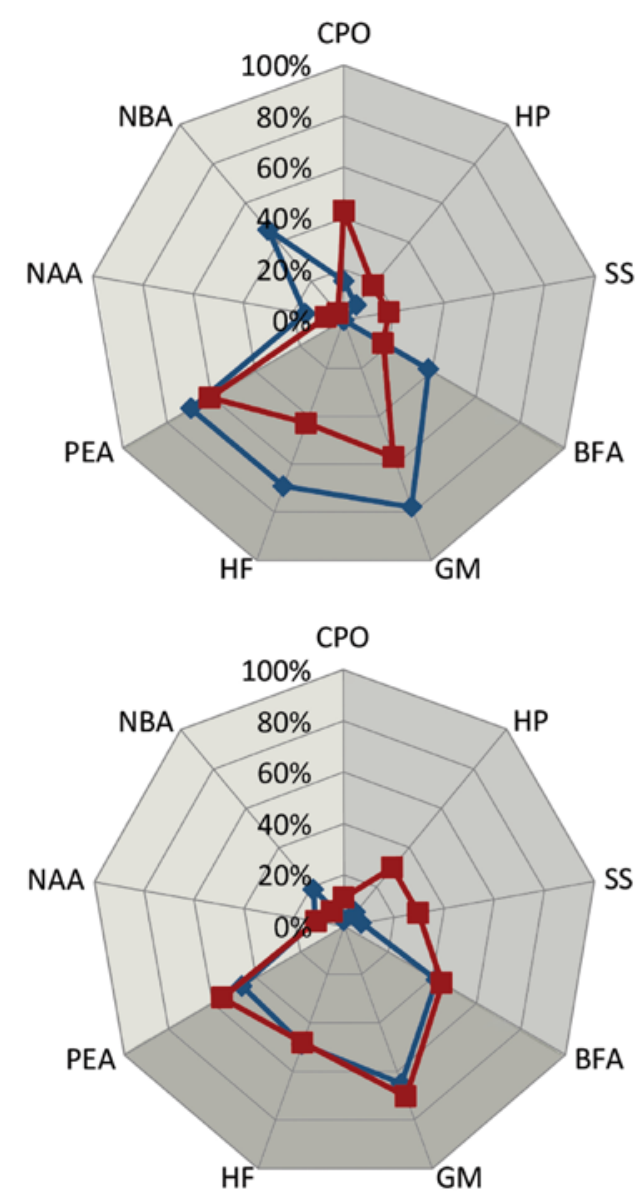

\section{$\underline{0-4 \text { years }}$}

\begin{tabular}{l|l} 
CPO: Change People's Opinion & Identity \\
HP: Highlight Personality & Reasons \\
SS: Suits my Style &
\end{tabular}

\begin{tabular}{l|c} 
BFA: Both Functionality and Aesthetics & Functional \\
GM: Great Mobility & Reasons \\
HF: High Functionality &
\end{tabular}

PEA: Participation in Everyday Activities

NAA: Not Attract Attention

Social

NBA: Normal Body Appearance

Figure 4 The reasons due to which the participants from Greece (GR) and the UK who had their amputation 0 to 4 years ago (up) and five years ago or more (down) chose the prosthetic limb they prefer.

\section{Discussion}

Although the findings are not representative of the population, it is clear that RP and FP are the most broadly used prosthetic limbs in both countries, while EP is not so popular among prosthetic users, especially in Greece. This is not surprising, as EP constitutes a new type of prosthesis that has been developed during the last decade. Nevertheless, the findings show that a very large number of people are not satisfied with the prosthetic limb(s) they own. This is in accordance with the findings of the study that Cairns et al. (2014) conducted. The analysis of participants' opinion regarding their appearance and the prosthetic limb they own presents similarities in both countries, as it shows that $\mathrm{RP}$ creates the most negative feelings to users since it presents the lowest percentage of positive effect. Figure 5 shows the prostheses owned (columns) versus the preferable prostheses (sections of columns) of participants who believe that their prosthetic limbs affect their appearance negatively. As it can be noticed, participants who own RP would like to use FP, while most of the participants who own FP and they are not satisfied would like to use EP. Additionally, none of the participants who already own EP answered that EP negatively affect their appearance. However, as the sample of people who own EP is very small further investigation is necessary.

Nguyen (2013) supports the existence of a distinction between the two sexes regarding the reasons they use the prostheses and points out that women are more concerned than men about identity and body image reasons, as they worry about their image and attractiveness. This is in accordance with the findings of the study and the analysis of the reasons due to which participants chose the prosthetic limb they prefer. Age seems to be a variable independent of culture; however, the results show that age affects the preferences of people to a great extent as in both countries EP are more preferable to younger participants and least preferable to those who are over 60 years old. 


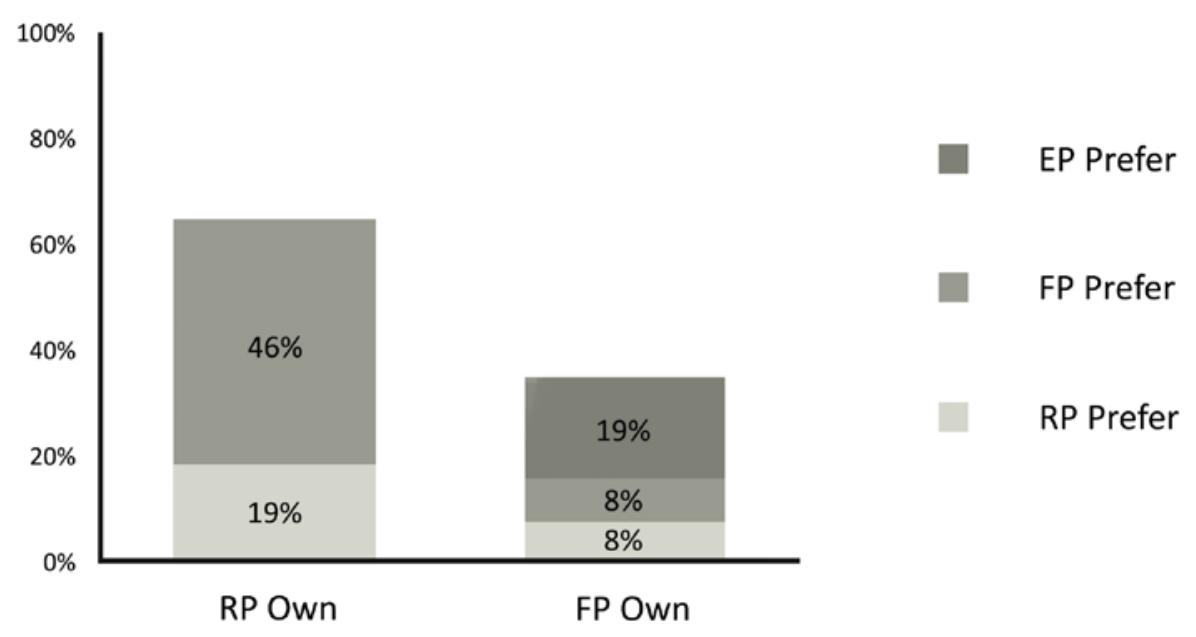

Figure 5 The total number of participants who answered that the prostheses they own (columns) affects their appearance negatively. The segments of each column show the prostheses participants prefer.

Interest presents the fact that although Greek participants are concerned about social reasons and try not to attract the attention of people to the limb loss, many Greek people chose EP, which purpose is to highlight wearer's uniqueness and identity; a purpose contrary to the values of Greek culture as a collectivism society with high uncertainty avoidance and power distance. However, the analysis shows that only the Greek participants who live in cities chose EP. Thus, the area of residence seems to affect the preferences of people of $\mathrm{HC}$ societies, probably due to the collectivism orientation they have, as well as stigma, which can easily be spread to collectivism societies, such as Greek villages. Thus, in order not to be stigmatised by the society in which they live, people try to use prostheses that will not attract people's attention to the limb loss. Furthermore, the higher rate of EP in preferences of Greek people who live in cities verifies the investigations which support that the urban societies of Greece are in a transitional phase from collectivism to individualism societies (Georgas, 1989; Pouliasi \& Verkuyten, 2011).

Nguyen (2013) points out that amputees are not concerned about the appearance of their prosthetic $\operatorname{limb}(\mathrm{s})$ when they are at the stage of recovery (after amputation) and only when they accept their limb loss do they start thinking about how the prosthetic limb affects their image. This is supported by the findings of the study which shows that the percentage of RP and EP is higher for participants who had the amputation more than five years ago. Furthermore, the reasons due to which participant chose the prosthetic limb they prefer with respect to the years that have been passed since the amputation constitutes a factor that is affected by the culture as Greek participants worry about the impact that amputation will have in their social life and environment, whilst participants from the UK are more concerned about the impact of amputation in their personality and identity. Based on the theories regarding $\mathrm{HC}$ and $\mathrm{LC}$ societies and the analysis of the reasons it can be assumed that when amputees from collectivism societies realise that people around them, as well as society accept the limb loss, their social anxiety will be decreased. On the other hand, the anxiety of people from LC societies will be easier decreased when they accept their new body image or maintain their previous identity.

As it can be noticed from the analysis of the participants' preferences towards the three types of prostheses with respect to the cause of the limb loss, RP is the least preferable type only in case of trauma. Furthermore, the analysis of the reasons shows that in case of limb loss due to disease, participants from both countries are concerned about social reasons. This may be due to the fact that when the amputation is a result of disease, people worry about the opinion that others have towards them and want to prove that they remain capable people and not a vulnerable group in order to reduce the stigmatisation of illness. When the limb loss does not happen suddenly in their life, as a congenital limb loss, people develop their identity based on that and as a result, they do not 
have the need to change people's opinion. The findings concerning the cause of amputation are also supported by the literature regarding the cause in the industrialised and non-industrialised countries (Esquenazi, 2004; Hagberg \& Brånemark, 2001). More specifically, in the UK (industrialised) the majority of the participants said that their limb loss occurred because of disease, while in Greece (non-industrialised) the main cause of amputation is trauma/ accident reasons. Congenital limb loss is the last reason in both countries, which is also in accordance with Esquenazi (2004) who says that the percentage of people with congenital limb loss is low in comparison with those of other reasons.

Although the contribution of the study to the design knowledge of prosthetic limbs needs more investigation, it is the author's opinion that the first step that needs to be taken in order to change society's opinion towards people with limb loss is to inform the people in the area of the design of prostheses of the preferences that users in different cultures have towards prostheses. This should lead to social innovation and the possibility of eliminating stigmatisation by increasing patient's confidence.

\subsection{Limitations of the study}

One of the limitations of the study is the sample of the research. The author acknowledges the fact that the sample is not representative of the population and this may have led to biased conclusions. However, as the aim of the study is to understand generally the preferences that people with limb loss have towards the various types of prostheses the sampling methods were deemed to be suitable for the purpose of the survey. Another limitation is the fact that although Greece and the UK present different cultural contexts, both of them are in Europe and as a result, their cultures may have been affected due to the homogeneity that globalisation causes.

\section{Conclusions}

The survey has been conducted in the UK and Greece and its aim is to investigate the preferences of people with limb loss towards the three types of prostheses (RP, FP, EP) and whether their preferences are affected by the culture in which they live, as a first step that can be done in order to bring societies closer to social innovation. The aim of the survey has been met and as the findings show, culture does not seem to affect the hierarchy of the preferences with FP being the most preferable prostheses and RP the least. The insights regarding the demographic and disability related variables with respect to the culture of the two countries (objective 2) have been gathered, and the reasons due to which participants have chosen the prosthetic limb they prefer based on the variables and culture (objective 3 ) have been explored. More specifically, in Greece the majority of participants are concerned about social reasons and the influence the limb loss will have in their social life, probably due to stigma whilst in the UK, participants' concerns focus on the consequences that amputation will have in their personality and identity. However, as the findings of the study are not clear, the key criteria that drive users' preferences with respect to the culture cannot be established (objective 4). Although age and cause of amputation seem two variables independent of culture, further investigations are necessary to be conducted in order to particularly test the influence of sex, age, area of residence, cause of amputation and the years wear prostheses, on people's preferences.

Furthermore, the fact that EP is second in people's preferences in both countries appear to be contrary to the theories of $\mathrm{HC} / \mathrm{LC}$ societies and the theory of collectivism/ individualism (objective 1), and supports the investigations which show that societies such as Greece are in a transitional era and many people with limb loss feel confident about themselves and they are ready to defend the fact that they do not consider themselves to be disabled, but as active people who can contribute to society. However, the vertical comparison of participants' preferences regarding EP indicates that the percentages of EP are higher in the UK (LC) than in Greece $(\mathrm{HC})$ in almost every subgroup, demonstrating that culture still plays a role in people's preferences albeit to a different degree in the different cultures. 


\section{References}

The ALLELES Design Studio Ltd. (2017). Team. Retrieved October 23, 2017, from https://www.alleles.ca/

Cairns, N., Murray, K., Corney, J., \& McFadyen, A. (2014). Satisfaction with cosmesis and priorities for cosmesis design reported by lower limb amputees in the United Kingdom: Instrument development and results. Prosthetics and Orthotics International, 38(6), 467-73. https://doi.org/10.1177/0309364613512149

Cohen, L., Manion, L. \& Morrison, K. (2011). Research Methods in Education (7th ed). New York, NY: Routledge.

Deal, M. (2003). Disabled people's attitudes toward other impairment groups: a hierarchy of impairments. Disability \& Society, 18(7), 897-910. https://doi.org/10.1080/0968759032000127317

Esquenazi, A. (2004). Amputation rehabilitation and prosthetic restoration. From surgery to community reintegration. Disability and Rehabilitation, 33(4), 1314-1323. https://doi.org/10.1682/JRRD.2003.06.0102

Fillauer. (2018). Lower Extremity Prosthetics: Dream Skin. [Image of product]. Retrieved January 30, 2018, from http://fillauer.com/Lower-Extremity-Prosthetics/cosmetic-covers/

Georgas, J. (1989). Changing Family Values in Greece: From Collectivist to Individualistic. Journal of CrossCultural Psychology, 20(1), 80-91.

Goncalo, J. A., \& Staw, B. M. (2006). Individualism-collectivism and group creativity. Organizational Behavior and Human Decision Processes, 100(1), 96-109. https://doi.org/10.1016/j.obhdp.2005.11.003

Grames, M., \& Leverentz, C. (2010). Attitudes Toward Persons with Disabilities: A Comparison of Chinese and American Students. UW-L Journal of Undergraduate Research XIII, 1-6. https://doi.org/10.1037/e566842012-669

Green, S., Davis, C., Karshmer, E., Marsh, R. \& Straight, B. (2005). Living Stigma : The Impact of Labeling, Stereotyping, Separation, Status Loss, and Discrimination in the Lives of Individuals with Disabilities and Their Families. Sociological Inquiry, 75(2), 197-215.

Hagberg, K., \& Brånemark, R. (2001). Consequences of non-vascular trans-femoral amputation: a survey of quality of life, prosthetic use and problems. Prosthetics and Orthotics International, 25(3), 186-94. https://doi.org/10.1080/03093640108726601

Hall, M. L., \& Orzada, B. T. (2013). Expressive Prostheses: Meaning and Significance. Fashion Practice: The Journal of Design, Creative Process \& the Fashion, 5(1), 9-32. https://doi.org/10.2752/175693813X13559997788682

Hofstede, G. (1984). Cultural dimensions in management and planning. Asia Pacific Journal of Management, 1(January), 81-99. https://doi.org/10.1007/BF01733682

Kim, E. (2010, September 7). Aviya Serfaty: Prosthetic leg for women. Retrieved October 23, 2017, from https://www.designboom.com/design/aviya-serfaty-prosthetic-leg-for-women/

Kongprasert, N. (2012). How To Extract Knowledge From Fashion Experts Through Emotional Design Approach. International Conference on Marketing Srudies, (August), 1-11.

McCracken, G. (1986). Culture and Consumption: A Theoretical Account of the Structure and Movement of the Cultural Meaning of Consumer Goods. The Journal of Consumer Research, 3(1), 71-84.

McDonagh, D., Bruseberg, A., \& Haslam, C. (2002). Visual product evaluation: Exploring users' emotional relationships with products. Applied Ergonomics, 33(3), 231-240. https://doi.org/10.1016/S00036870(02)00008-X

Mullins, A. (2009). My 12 pairs of legs [Video file]. Retrieved August 7, 2017, from https://www.ted.com/talks/aimee mullins prosthetic aesthetics

Murray, C. D. (2005). The social meanings of prosthesis use. Journal of Health Psychology, 10(3), 425-41. https://doi.org/10.1177/1359105305051431

Nguyen, D. D. (2013). The Beauty of prostheses: Designing for Female Amputees. University of New Mexico.

Össur. (2018). The RHEO Knee. [Image on Website]. Retrieved February 20, 2018, from https://www.ossur.com/corporate/newslist/670-ossur-announces-world-8217-s-first-integrated-bionicprosthetic-leg

Otto Bock HealthCare GmbH. (2017). bebionic Hand: Wrist Options. [Image on Website]. Retrieved October 23, 2017, from http://bebionic.com/the hand/bebionic3 wrist options

Papadopoulos, C. (2009). Stigma towards people with mental health problems: An individualism-collectivism cross-cultural comparison. Middlesex University.

Pouliasi, K., \& Verkuyten, M. (2011). Self-Evaluations, Psychological Well-Being, and Cultural Context: The Changing Greek Society. Journal of Cross-Cultural Psychology, 42(5), 875-890. https://doi.org/10.1177/0022022110381118

Prosthetic devices. (n.d.). Miller-Keane Encyclopedia and Dictionary of Medicine, Nursing, and Allied Health,. Retrieved October 23, 2017, from https://medical-dictionary.thefreedictionary.com/Prosthetic+devices 
Pullin, G. (2009). Design meets disability. London: MIT Press.

Riddell, S. \& Watson, N.. (2003). Disability, Culture and Identity. New York, NY: Routledge.

Robson, C. \& McCartan, K. (2016). Real World Research (4th ed.). UK: John Wiley \& Sons Ltd.

Rybarczyk, B., Nyenhuis, D., Nicholas, J., Schulz, R., Alioto, R., \& Blair, C. (1992). Social discomfort and depression in a sample of adults with leg amputations. Archives of Physical Medicine and Rehabilitation, 73(December), 1169-1173. Retrieved from http://www.archives-pmr.org/article/0003-9993(92)90116E/pdf

Saetermoe, C. L., Scattone, D., \& Kim, K. H. (2001). Ethnicity and The Stigma of Disabilities. Psychology \& Health, 16(6), 699-714. https://doi.org/10.1080/08870440108405868

Sansoni, S., Wodehouse, A., \& Buis, A. (2014). The Aesthetics Of Prosthetic Design: From Theory To Practice. Proceedings of the 13th International Design Conference, 975-984. Dubrovnik, Croatia: DESIGN

Sansoni, S., Wodehouse, A., \& Buis, A. (2015). The Aesthetic Appeal of Prosthetic Limbs and the Uncanny Valley: The Role of Rersonal Characteristics in Attraction. International Journal of Design, 9(1), 67-81.

Sethna, Z. \& Blythe, J. (2016). Consumer behaviour (3rd ed.). (M. Waters, Ed.). Glasgow, Great Britain: SAGE Publications Ltd.

Simon, L. (2014). Women and Fashion. Journal of Women's History, 26(4), 164-171. https://doi.org/10.1353/jowh.2014.0061

Summit, S. (2011). Beautiful artificial limbs [Video file]. Retrieved August 7, 2017, from https://www.ted.com/talks/scott_summit beautiful_artificial limbs

SummitID. (2017). Transfemoral Monocoque Polyaxial Study. [Image of product]. Retrieved August 7, 2017, from http://www.summitid.com/\#/fairings-1/

Susman, J. (1994). Disability, Stigma and Deviance. Social Science \& Medicine, 38(I), 15-22.

The alternative limb project. (2018). Realistic limbs. [Image of product]. Retrieved January 30, 2018, from http://www.thealternativelimbproject.com/fullscreen/realistic-limbs/

The alternative limb project (i). (2018). Alternative limbs: Synchronised. [Image of product]. Retrieved January 30, 2018, from http://www.thealternativelimbproject.com/types/alternative-limbs/

Tsikriktsis, N. (2002). Does Culture Influence Web Site Quality Expectations?: An Empirical Study. Journal of Service Research, 5(2), 101-112. https://doi.org/10.1177/109467002237490

Vainshtein, O. (2011). I have a suitcase just full of legs because I need options for different clothing: Accessorizing Bodyscapes. Fashion Theory - Journal of Dress Body and Culture, 16(2), 139-170. https://doi.org/10.2752/175174112X13274987924014

Werner, S., \& Shulman, C. (2015). Does type of disability make a difference in affiliate stigma among family caregivers of individuals with autism, intellectual disability or physical disability?, 59(march), 272-283. https://doi.org/10.1111/jir.12136

Westbrook, M. T., Legge, V. \& Pennay, M. (1993). Attitudes Towards Disabilities Multicultural. Social Science \& Medicine, 36(5), 615-623.

Würtz, E. (2005). Intercultural communication on web sites: a cross-cultural analysis of web sites from highcontext cultures and low-context cultures. Journal of Computer-Mediated Communication, 11(1), 274-299. https://doi.org/10.1111/j.1083-6101.2006.00013.x

Yaveroglu, I. S. \& Donthu, N. (2002). Cultural Influences on the Diffusion of New Products. Journal of International Consumer Marketing, 14(4), 5. https://doi.org/10.1300/J046v14n04

Zaromatidis, K., Papadaki, A., \& Gilde, A. (1999). A cross-cultural comparison of attitudes toward persons with disabilities: Greeks and Greek-Americans. Psychological Reports, 84(3 Pt 2), 1189-1196.

https://doi.org/10.2466/pr0.1999.84.3c.1189

Zola, I. K. (1993). Self, identity and the naming question: Reflections on the language of disability. Social Science and Medicine, 36(2), 167-173. https://doi.org/10.1016/0277-9536(93)90208-L

About the Authors:

Vlachaki Anna has a background in Product and Interior Design. Currently she is a Postgraduate Research Student at Loughborough Design School, Loughborough University, UK. Her PhD focuses on the expressive prostheses with further interest in emotional design and Additive Manufacture.

Dr Paterson Abby M.J. is a Lecturer in Industrial Design and Technology at Loughborough Design School, Loughborough University, UK. Dr Paterson specialises in 3D scanning, Computer Aided Design (CAD) and digital, automated fabrication (including CNC milling and Additive Manufacture). 
Dr Porter C. Samantha is a Senior Lecturer in Design Ergonomics at Loughborough Design School, Loughborough University, UK, a fellow of the Ergonomics Society and an Associate Fellow of the British Psychological Society. Her background is in ergonomics, applied psychology and design ergonomics.

Prof Bibb Richard J. is a Professor of Medical Applications of Design at Loughborough Design School, Loughborough University, UK. Professor Bibb's primary area of research explores the effective application of advanced design and product development technologies in medicine, healthcare, surgery and rehabilitation. 